\title{
On the Determination of the Public Debt
}

\section{Citation}

Barro, Robert J. 1979. On the determination of the public debt. Journal of Political Economy 87(5): 940-971.

\section{Published Version}

doi:10.1086/260807

\section{Permanent link}

http://nrs.harvard.edu/urn-3:HUL.InstRepos:3451400

\section{Terms of Use}

This article was downloaded from Harvard University's DASH repository, and is made available under the terms and conditions applicable to Other Posted Material, as set forth at http:// nrs.harvard.edu/urn-3:HUL.InstRepos:dash.current.terms-of-use\#LAA

\section{Share Your Story}

The Harvard community has made this article openly available.

Please share how this access benefits you. Submit a story.

Accessibility 


\title{
On the Determination of the Public Debt
}

\section{Robert J. Barro}

University of Rochester

\begin{abstract}
A public debt theory is constructed in which the Ricardian invariance theorem is valid as a first-order proposition but where the dependence of excess burden on the timing of taxation implies an optimal time path of debt issue. A central proposition is that deficits are varied in order to maintain expected constancy in tax rates. This behavior implies a positive effect on debt issue of temporary increases in government spending (as in wartime), a countercyclical response of debt to temporary income movements, and a one-to-one effect of expected inflation on nominal debt growth. Debt issue would be invariant with the outstanding debt-income ratio and, except for a minor effect, with the level of government spending. Hypotheses are tested on U.S. data since World War I. Results are basically in accord with the theory. It also turns out that a small set of explanatory variables can account for the principal movements in interest-bearing federal debt since the 1920s.
\end{abstract}

In a previous paper (Barro 1974) I discussed the "Ricardian" equivalence theorem on public debt ${ }^{1}$-that is, the proposition that shifts between debt and tax finance for a given amount of public expenditure would have no first-order effect on the real interest rate, volume of private investment, etc. This theorem surely remains controversial, although it seems to be evolving into a respectable viewpoint. In any event, proponents of the Ricardian view that the choice between debt

This research is being supported by the National Science Foundation. I have benefited from comments by Paul Evans, Milton Friedman, Bob Hall, Elhanan Helpman, Michael Parkin, John Shoven, David Starrett, George Stigler, and C. C. von Weizsäcker.

${ }^{1}$ I am grateful to Buchanan (1976) for pointing out that I was discussing this topic. The Ricardian equivalence proposition is presented in Ricardo $(1951 a, 1951 b)$ and discussed in Buchanan (1958, chaps. 4 and 8). See O'Driscoll (1977) for an amusing discussion of whether Ricardo actually held to the Ricardian view.

[Journal of Political Economy, 1979, vol. 87, no. 5, pt. 1]

(C) 1979 by The University of Chicago. $0022-3808 / 79 / 8751-0003 \$ 02.56$ 
and taxes does not matter are left with an embarrassing absence of a theory of public debt creation. ${ }^{2}$ This paper develops a simple theory of "optimal" public finance that identifies some factors that would influence the choice between taxes and debt issue. The model accepts the Ricardian invariance theorem as a valid first-order proposition but introduces some second-order considerations involving the "excess burden" of taxation to obtain a determinate (optimal) amount of debt creation. It should be stressed that some typical features of public debt analysis, such as shifting of the tax burden to future generations, crowding out of private investment, etc., are excluded by the assumption that the Ricardian proposition is valid on the first order. Hence, the analysis concentrates on less familiar issues that would be dominated by the usual first-order effects-if these effects were, in fact, pertinent to the choice between debt and taxes.

The theoretical model is used to formulate several testable propositions concerning the determination of public debt issue. Principal hypotheses involve the positive effect on debt issue of temporary increases in government spending (especially important during war and postwar periods), the negative effect of temporary increases in income-that is, a countercyclical response of debt issue, and a oneto-one effect of the expected inflation rate on the growth rate of nominal debt. The theory also implies that the growth rate of debt would be independent of the debt-income ratio and would be affected at most in a minor way by the level of government expenditure.

The hypotheses are tested using the time-series data on public debt issue in the United States since World War I. The results are basically in accord with the underlying theory. In particular, the relation between debt issue and a small set of explanatory variables seems to be reasonably stable since World War I. However, the magnitude of countercyclical debt response is significantly larger than that implied by the theory. Although this phenomenon does not seem to be of recent origin, it does suggest that some additional element-such as governmental attempts at stabilization policy-would be needed to account for this behavior.

\section{A Model of Public Debt Issue}

The model applies to a large national government that has jurisdiction over a population of exogenous size. The analysis therefore neglects any effects of public debt policy on migration, which would be an important consideration for a local government. The govern-

\footnotetext{
${ }^{2}$ However, opponents of the Ricardian view seem also to lack an interesting positive theory of the public debt.
} 
ment is assumed to finance its expenditures through two methods: current taxation and public debt issue. I do not deal here with currency issue, although for some purposes this type of finance could be included as one form of current taxation. The composition of taxes, by type or degree of graduation, is taken as given. The volume of real government expenditure, aside from interest payments on the public debt, during period $t$ is denoted by $G_{t}$ and is assumed to be exogenous. Hence, the present analysis does not deal with the determination of the size of the public sector. Future values of $G$ and of other exogenous variables are treated as though known with certainty. Real tax revenue obtained by the government in each period is designated by $\tau_{t}$, and aggregate real income (treated as exogenous) by $Y_{t}$. The real stock of public debt outstanding at the end of period $t$ is denoted by $b_{t}$, where this debt can be assumed at this stage to take the form of one-period, single-coupon bonds that are issued at par. I assume initially that the price level, $P$, is (and is expected to be) constant over time, and the real (=nominal) rate of return on public and private debts, $r$, is also a constant. ${ }^{3}$ The government's budget equation in each period is

$$
G_{t}+r b_{t-1}=\tau_{t}+\left(b_{t}-b_{t-1}\right),
$$

where interest payments during period $t$ are assumed to apply to the stock of debt outstanding at the beginning of the period.

The government's budget equation at each date $t$, together with an additional condition that rules out perpetual debt finance, implies the overall budget constraint,

$$
\sum_{1}^{\infty}\left[G_{t} /(1+r)^{t}\right]+b_{0}=\sum_{1}^{\infty}\left[\tau_{t} /(1+r)^{t}\right] .
$$

This condition-which equates the present value of government expenditure (aside from interest payments) plus initial debt to the present value of taxes-follows from equation (1) as long as $b$ is constrained to grow asymptotically at a rate below $r{ }^{4}$

\footnotetext{
${ }^{3}$ Implicit in this condition is the assumption that the required real rate of return on public debt, relative to that on private debt, is invariant with the quantity of government debt outstanding. If the quantity of public debt approaches the government's collateral-in the sense of the present value of its future taxing capacity-then the risk of the government's default would have to be taken into account (see Barro 1976 $b$, p. 343). Alternatively, if government debt were perceived as net wealth by the private sector, then the quantity of debt could influence real rates of return in the economy (see, e.g., Barro 1974, p. 1096).

${ }^{4}$ In the efficient case where $r$ exceeds the growth rate of real income, this condition requires a bound on the asymptotic debt-income ratio (see Barro 1976b, pp. 343-45). Presumably, this ratio cannot, in fact, exceed the finite value implied by the government's collateral (n. 3 above).
} 
The sum of the present value of government expenditures and the initial debt level, which appears on the left side of equation (2) and is exogenously given, determines the present value of government tax receipts. However, the fixity of this last present value leaves open the determination of the time pattern of taxes. It is assumed that taxation involves not only a one-to-one transfer of purchasing power from individuals to the government but also some collection costs and/or indirect misallocation costs that are imposed on the private economy. That is, the "production" of government revenue involves the using up of some resources in the sense of costs that are often referred to as "deadweight losses" or "excess burdens." For a given present value of net tax revenues (as fixed by the present value of expenditures and the initial debt level), the present value of these extra costs would generally depend on the distribution of taxes by type and timing. The present analysis, which focuses on the timing of taxes, abstracts from the determination of tax composition at a point in time. Essentially, the analysis of timing is conditional on the selection of an "optimal" tax composition that underlies the "production function" relation between net tax receipts and "excess burden" that is specified below.

For the case of direct collection costs for administration, enforcement, and so on, let $Z_{t}$ represent the real cost incurred and $Y_{t}$ the real national income in period $t .{ }^{5} \mathrm{I}$ assume that $Z_{t}$ depends positively, with a positive second derivative, on the total net tax take for the period $\tau_{t}$ and negatively on the pool of contemporaneously taxable resources $Y_{t}$, but not on the values of taxes or incomes in other periods. Further, I neglect any special relation of collection costs to the contemporaneous government spending level $G_{t}{ }^{6}$ Finally, I assume the homogeneity condition that a doubling of net tax collections $\tau_{t}$ and potential tax pool $Y_{t}$ doubles the collection $\cos Z_{t}$. Therefore, the collection cost for period $t$ can be written as

$$
Z_{t}=F\left(\tau_{t}, Y_{t}\right)=\tau_{t} f\left(\tau_{t} / Y_{t}\right),
$$

where $f^{\prime}>0$, and the function $f$ is assumed to be invariant over time. The present value of collection costs is then given by

$$
Z=\sum_{t=1}^{\infty} \tau_{t} f\left(\tau_{t} / Y_{t}\right) /(1+r)^{t} .
$$

\footnotetext{
${ }^{5}$ I have not included the collection costs as components of government spending in eq. (1), although the analysis could be altered in that manner without affecting any substantive results. Independence of national income levels from the choice of the time path of taxes is assumed to hold as a first-order approximation-essentially, the deadweight losses from taxation are assumed to constitute only a small fraction of GNP.

${ }^{6}$ Such an effect might arise if, e.g., the influence of war on "patriotism" lowers the administrative costs of raising taxes during wartime.
} 
At the present time (date 1) the government is confronted by an exogenous series of planned expenditures, $G_{1}, G_{2}, \ldots$, which it must finance at each date; by a series of (anticipated) real income values, $Y_{1}$, $Y_{2}, \ldots$; the interest rate $r$; and an initial stock of debt, $b_{0}$. The overall budget condition in equation (2) fixes the present value of net tax collections. Given this present value, the government's objective is taken to be the minimization of the present value of the resources consumed by the process of revenue generation, $Z$, as shown in equation (4). This general form of the objective is similar to ones set up by Prescott (1977) and Barro (1976a).

The assumed objective of the government-that it pursues a costminimization policy involving the economization of revenue-raising costs-can be reconciled with various models of public sector behavior. For example, the setup seems consistent with a public-interest theory of government, with a model of self-interested politicians who are subject to "effective" electoral control, and with a model of a political dictator who maximizes own utility. The objective would not seem to apply if the institutional structure were such that "political income" was directly related to the amount of deadweight loss generated by the government.

The government's optimization problem amounts to choosing $\tau_{1}, \tau_{2}$, ..., to minimize the present value of revenue-raising costs, subject to the form of the cost function in equation (4) and the overall budget constraint in equation (2). The resulting first-order conditions, which can be obtained in the usual manner, require the marginal collection cost for raising taxes- $\partial Z_{t} / \partial \tau_{t}$-to be the same in all periods (without regard to the value of $r$, because tax revenue and the associated collection cost arise at the same point in time). With the homogeneous specification of costs in equation (4), these conditions require the tax rate, $\tau / Y$, to be equal in all periods. The (planned) constancy of this ratio is the key to the subsequent analysis. ${ }^{7}$ Given that the tax-income

\footnotetext{
${ }^{7}$ The choice of taxes over time can also be considered in terms of an objective that encompasses distortion costs on the private economy. I have considered only a simple model in which the representative individual receives utility from leisure and a single consumption good in each period, where any satisfaction provided by government services in various periods is separable from the utility provided by consumption and leisure, where interest income is untaxed, and where the present values of all producer prices are constant. This constancy would obtain if production were subject to constant returns to scale (which means that the model does not deal with capital accumulation in a serious way) and if the interest rate were fixed. One justification for the latter would be a small-country setting in which the domestic interest rate was tied to the exogenous return available internationally. The optimal taxation literature, as in Sandmo (1974) and Sadka (1977), can then be applied to determine the time pattern of consumption and leisure taxes that maximizes the utility of the representative individual, given the present value of tax collections. E.g., for the case where leisure in each period is untaxed, uniform consumption taxation over time emerges if the compensated elasticity of consumer demand in period $i$ with respect to the present-value wage for any
} 
ratio is constant, the level of taxes in each period is determined from the given values of $\left(Y_{1}, \ldots\right),\left(G_{1}, \ldots\right), r$, and $b_{0}$ in order to conform with the overall budget condition set out in equation (2). These values for taxes imply values for the government deficit in each period, $b_{t}-b_{t-1}$, in accordance with equation (1). The properties of the solution are illustrated below for particular specifications of the time paths of $Y$ and $G$.

\section{Constant Income and Government Expenditure}

If $Y$ is constant over time, the constancy of $\tau / Y$ implies constancy of $\tau$. If $G$ is also constant, the level of $\tau$ is determined immediately from equation (2), which specializes here to $G / r+b_{0}=\tau / r$, so that $\tau=G+$ $r b_{0}$. It follows from equation (1) that the government's budget is always in balance-that is, $b_{t}=b_{t-1}=b_{0}$ for all $t$. A notable aspect of this solution is that the initial debt is not amortized. The steady-state value of public debt is determined entirely by its initial value rather than as a function of $G, Y, r$, or the form of the collection cost function, $f$, in equation (3). A related implication is that the government deficit, $b_{t}-b_{t-1}$, is determined (to equal zero) independently of the values of $b_{0}, G, Y, r$, or the form of the $f$-function. This type of result continues to apply when complications are introduced into the specified time paths of $G$ and $Y$.

\section{Constant Rate of Growth of Income and Government Expenditure}

Suppose now that aggregate real income grows at the constant rate $\rho$, so that $Y_{t}=Y_{0}(1+\rho)^{t}$. In order for the present value of future income to be finite (i.e., to be in the efficient case referred to in $n .4$ above), it must be that $r>\rho$. Government expenditure is assumed to grow at rate $\gamma$, so that $G_{t}=G_{0}(1+\gamma)^{t}$. In order for $G / Y<1$ to hold at all times, it must be that $\gamma \leqslant \rho<r .{ }^{8}$ Clearly, $\rho=\gamma$ is the only specification within

period $j$ is independent of the index $i$. (The results from Sandmo [p. 705, eq. 22] and Sadka [p. 389, eq. 8] can be extended to obtain this conclusion.) Essentially, this condition rules out any special relationship of complementarity or substitutability between leisure at date $j$ and consumption at various dates-which would be violated if, e.g., contemporaneous leisure were a strong complement for consumption. Sandmo's analysis [p. 705, eq. 24] implies that the desired condition obtains if the utility function is weakly separable between work and consumption and homogeneous in consumption goods (so that the income elasticities for consumption at various dates are equal). More generally, it seems that approximate constancy of optimal tax rates would hold if leisure at one date were a close substitute for leisure at other dates and if consumption at one date were a close substitute for consumption at other dates. See Kydland and Prescott $(1978$, p. 18) on this point.

${ }^{8}$ However, it is clear empirically that $\gamma>\rho$ can prevail for long periods. E.g., for the United States from 1890 to 1976 the average growth rate of real GNP was 3.1 percent per year, while that of real federal expenditure was 5.8 percent per year. 
the constant growth rate setup that allows for a positive, finite steadystate value of $G / Y$. However, examination of results for cases where $\rho$ $\neq \gamma$ is permitted provides qualitative insights into more complicated situations where differences between $\rho$ and $\gamma$ prevail over finite intervals.

Since the tax-income ratio is still constant in the optimal solution it follows that taxes grow at the same rate as income-that is, $\tau_{t}=\tau_{0}(1+$ $\rho)^{t}$. Using the budget condition of equation (2) leads eventually to the result, $\tau_{0}=[(r-\rho) /(1+\rho)]\left[G_{0}(1+\gamma) /(r-\gamma)+b_{0}\right]$, which can be used to determine the value of taxes at any date. Using $\tau_{1}=\tau_{0}(1+\rho), G_{1}=$ $G_{0}(1+\gamma)$, and the government budget condition in equation (1) implies that the deficit in the current period is

$$
b_{1}-b_{0}=\rho b_{0}+[(\rho-\gamma) /(r-\gamma)] G_{1} .
$$

For the case where income and government expenditure grow at a common rate, $\rho=\gamma$, the conclusion from this extension is that (real) government debt also grows at this rate $-\left(b_{1}-b_{0}\right) / b_{0}=\rho$-rather than remaining constant over time. It is now the ratio of debt to income, $b / Y$, that remains fixed at its initial value, $b_{0} / Y_{0}$. The model therefore retains the property that the debt-income ratio is not determined within the model (by the values of $G / Y, r, \rho$, or the form of the $f$-function) but is rather fixed at its historically given "initial" value.

For $\rho \neq \gamma$ an additional effect is that the current deficit rises with $\rho$ and falls with $\gamma$ (for a given value of current government spending, $G_{1}$ ). When $\rho$ exceeds $\gamma$, future values of $G / Y$ will be lower than the current value. Consequently, the financing of expenditure becomes easier over time-in the sense of a diminished relative collection cost-so that the deferral of taxation is warranted. This deferral of taxation corresponds to current deficit finance, as reflected in the higher value of $b_{1}-b_{0}{ }^{9}$

\section{Transitory Income and Government Expenditure}

An empirically important extension to the model concerns temporary departures of government spending or aggregate income from "normal" values. This analysis applies especially to the role of wartime expenditures and depressions-both viewed as transitory phenomena-in the government debt creation process.

\footnotetext{
${ }^{9}$ In terms of the growth rate of $b$, the division of eq. (5) by $b_{0}$ indicates that the extra term is $[(\rho-\gamma) /(r-\gamma)]\left(G_{1} / b_{0}\right)$. If $\rho>\gamma, b$ grows faster than $G$ over time, and the ratio $G_{t} / b_{t-1}$ approaches zero. Hence, the asymptotic growth rate of $b$ would still be $\rho$ (and the asymptotic value of $G / Y$ would be zero). Of course, if $\rho<\gamma, G / Y$ would approach infinity, which would be a meaningless result. The main interest in the $(\rho-\gamma)$ term in eq. (5) would arise in situations where $\rho \neq \gamma$ applies over some finite period, but not in the steady state. The result for this more complicated situation would correspond qualitatively to that indicated in eq. (5).
} 
Suppose that current government expenditure departs by a fraction $\epsilon$ from its trend value-that is, $G_{1}=(1+\epsilon) G_{0}(1+\rho)$, and that the current value of income differs from its trend value by the fraction $u$-that is, $Y_{1}=(1+u) Y_{0}(1+\rho)$, where $G_{0}$ and $Y_{0}$ are assumed (defined) to be along the respective trend lines. For convenience, I deal here with a case where the trend growth rates of $G$ and $Y$ are equal, since the main effect of unequal growth rates is brought out in equation (5). The expected departure of $G$ from trend is assumed to persist (by the fraction $\epsilon$ ) for $k$ periods, while the departure of $Y$ from trend is assumed to persist (by the fraction $u$ ) for $n$ periods. ${ }^{10}$ This specification could be generalized in obvious ways-for example, by altering the assumption that the anticipated fractional departures of $G$ and $Y$ away from trend, $\epsilon$ and $u$, were precisely constant over $k$ and $n$ periods, respectively. However, the present setup brings out two significant elements: first, the role of the magnitude of the departure of current $G$ and $Y$ from trend and, second, the impact of the perceived duration of departures from trend.

Optimal public finance still requires a constant (planned) ratio of taxes to income at all points in time. Accordingly, from date $n+1$ onward, planned taxes still grow along with income at rate $\rho$. However, because of the transitory (+ or - ) income over the first $n$ periods, the taxes over this interval depart from trend by the factor, 1 $+u$. Using these facts and the budget condition of equation (2)which now includes the transitory government spending over the first $k$ periods-it is possible to determine taxes at all points in time. The solution can be written in the form

$$
\begin{aligned}
\tau_{t}= & {[1 /(1+u)] \tau_{1}(1+\rho)^{t-1} \text { for } t=n+1, n+2, \ldots, } \\
\tau_{t}= & \tau_{1}(1+\rho)^{t-1} \quad \text { for } t=1, \ldots, n, \\
\tau_{1}= & \frac{(1+u)}{(1+u)-u[(1+\rho) /(1+r)]^{n}}\left(G_{0}(1+\rho)+(r-\rho) b_{0}\right. \\
& \left.+\epsilon G_{0}(1+\rho)\left\{1-[(1+\rho) /(1+r)]^{k}\right\}\right) .
\end{aligned}
$$

The above expression for $\tau_{1}$, derived from the government's budget constraint in equation (2), can be interpreted as follows. The term in the right-hand parentheses measures the "permanent" level of required finance-the trend value of expenditures, $G_{0}(1+\rho)$, plus the interest on the initial debt less the part that is financed by issue of debt along with the trend growth of income, $(r-\rho) b_{0}$, plus the effect of transitory expenditures. This last item is the amount of current transitory expenditure, $\epsilon G_{0}(1+\rho)$, multiplied by a factor that accounts for duration. As $k \rightarrow 0$ (see n. 10 above) this factor approaches zero-that

\footnotetext{
${ }^{10}$ Although $k$ and $n$ must formally be integers within the present discrete framework, these restrictions are of no importance in interpreting the results.
} 
is, purely transitory current government expenditure has no effect on current taxation. As $k \rightarrow \infty$ the factor approaches unity (assuming $r<$ $\rho)$-signifying that the "transitory" component of government spending amounts in this case to permanent expenditure. Generally, the higher the expected duration of a given amount of current transitory government spending, the larger the amount of current taxation.

The other term on the right side of equation (6) accounts for transitory income. If the duration, $n$, of the departure of current income from trend were close to zero, then $\tau_{1}$ would be a multiple, $1+$ $u$, of the permanent level of finance (in order to equate the current tax-income ratio to the future ratio). As $n$ increases, the length of the period for which taxes will depart from trend by the factor $(1+u)$ rises, which (if $u$ is positive) diminishes the required amount of current taxation. As $n \rightarrow \infty$, the multiplication of trend income by $(1+u)$ becomes permanent, so that the first term on the right side of equation (6) approaches unity (assuming $r>\rho$ ). In this situation taxes correspond to the permanent level of finance at all times rather than being multiplied by $(1+u)$ over an interval of finite length $n$. Generally, current taxes are an increasing function of the amount of current transitory income, as measured by $(1+u)$, and a decreasing function of the anticipated duration, $n$, of this transitory income.

With current taxes determined from equation (6), the current government deficit follows from the budget condition in equation (1) as $b_{1}$ $-b_{0}=G_{1}+r b_{0}-\tau_{1} \simeq[(1+\rho) /(1+r)]^{k}\left[\epsilon G_{0}(1+\rho)\right]-[(1+\rho) /(1+$ $r)]^{n}\left[G_{0}(1+\rho)+r b_{0}\right] u+\rho b_{0}$, where the approximation involves neglecting the term, $u[(1+\rho) /(1+r)]^{n}$, relative to 1 . Letting $\bar{G}_{1}=G_{0}(1+$ $\rho)$ be the trend value of current government spending and $\bar{Y}_{1}=Y_{0}(1$ $+\rho)$ be the trend value of current income, the solution can be rewritten from the definitions of $\epsilon$ and $u$ as $b_{1}-b_{0} \simeq[(1+\rho) /(1+$ $r)]^{k}\left(G_{1}-\bar{G}_{1}\right)-[(1+\rho) /(1+r)]^{n}\left(\bar{G}_{1}+r b_{0}\right)\left[\left(Y_{1}-\bar{Y}_{1}\right) / \bar{Y}_{1}\right]+\rho b_{0}$, or, in growth rate terms,

$$
\begin{aligned}
\left(b_{1}-b_{0}\right) / b_{0} \simeq & {[(1+\rho) /(1+r)]^{k}\left(G_{1}-\bar{G}_{1}\right) / b_{0} } \\
& -[(1+\rho) /(1+r)]^{n}\left[\left(\bar{G}_{1}+r b_{0}\right) / b_{0}\right]\left[\left(Y_{1}-\bar{Y}_{1}\right) / \bar{Y}_{1}\right]+\rho .
\end{aligned}
$$

The growth rate of debt in equation (7) departs from the trend income growth rate, $\rho$, in accordance with the value of two variables. The first variable is the departure of current government spending from normal, $G_{1}-\bar{G}_{1}$, relative to the initial debt level. The coefficient of this variable, $[(1+\rho) /(1+r)]^{k}$, would be unity if the "extra" expenditure were entirely transitory $(k=0)$, less than unity (since $r>$ $\rho$ ) if the duration were finite, and would approach zero as $k$ approaches infinity (in which case the gap between $G_{1}$ and $\bar{G}_{1}$ would not 
actually represent a departure of spending from normal). The second variable is the proportional deviation of income from normal, $\left(Y_{1}-\right.$ $\left.\bar{Y}_{1}\right) / \bar{Y}_{1}$, multiplied by the normal level of government expenditure (including interest payments on the initial debt) relative to the initial debt. The coefficient of this variable, $[(1+\rho) /(1+r)]^{n}$, would be unity if departures of income from normal (booms and recessions) were entirely transitory $(n=0)$, less than unity if this duration were finite, and would approach zero as $n$ approaches infinity. If $k$ and $n$ are viewed as constants-that is, if systematic effects on perceived duration of transitory government expenditure or transitory income cannot be isolated-then the principal hypotheses derivable from equation (7) are that the $\left(G_{1}-\bar{G}_{1}\right)$ variable has a coefficient that is positive but less than one, while the $\left(Y_{1}-\bar{Y}_{1}\right) / \bar{Y}_{1}$ variable has a coefficient that is negative but less than one in magnitude. If the durations are themselves on the order of 2-5 years (corresponding roughly to the periods of business cycles and wars) and if the excess of $r$ over $\rho$ is in a range of 1-2 percent per year, then the magnitude of both coefficients is close to one. For example, if $r=5$ percent per year (recall that $r$ is a real rate of return) and $\rho=3.5$ percent per year, then a horizon $(k$ or $n)$ of 2 years implies a coefficient magnitude of 0.97 , while a horizon of 5 years implies a coefficient magnitude of $0.93{ }^{11}$

The response of the deficit to the income term in equation (7) corresponds partly to the "automatic stabilizer" property of a tax system by which revenues rise and the deficit falls with income for a given set of tax laws. ${ }^{12}$ These income-induced changes in tax revenues (and also in some components of federal expenditure) are, in principle, filtered out in the construction of a "full-employment surplus" (see U.S. Council of Economic Advisers [1962, pp. 78-81] for a discussion of this concept). However, the present analysis would also incorporate changes in the tax "structure"-which would usually be labeled as "discretionary" fiscal changes-that are a response to income fluctuations. Further, the present model rationalizes a system of tax laws that allows for an automatic procyclical pattern of revenues as a convenient mechanism for stabilizing the tax-income ratio. This

\footnotetext{
${ }^{11}$ The model can also be used to analyze the effect of anticipated future blips in government expenditure or income. Current taxes and, hence, the current deficit would be affected here only to the extent that these anticipated future departures from normal have a substantial duration. The effects can be illustrated by the $(\rho-\gamma)$ term in eq. (5) from the model in which the trend growth rates of $Y(\rho)$ and $G(\gamma)$ were unequal. The anticipation of higher future values of income relative to government spending when $\rho>\gamma$ implies less incentive for current taxation. Therefore, the current deficit increases with $\rho-\gamma$. Similarly, the expectation that future government expenditures—say, for social security benefits-will increase relative to income should stimulate current taxation and, hence, move the government budget toward surplus.

${ }^{12}$ Any automatic response of government expenditure to income would be held constant by the $G-\bar{G}$ term in eq. (7).
} 
rationale derives here from efficiency in revenue generation and not from stabilization policy considerations. ${ }^{13}$

The result in equation (7) implies that the debt-income ratio would be expected to remain constant on average but would rise in periods of abnormally high government spending or abnormally low aggregate income. However, as was also true in the simpler model above, the analysis does not determine a target or steady-state debt-income ratio. The ratio at any time reflects only the accumulation of realized values of government expenditure relative to normal and income relative to normal, which would have zero mean, ex ante, but do not have to add to zero, ex post. There is no force that causes the ratio of debt to income to approach some target value, which would itself depend on underlying parameters of the model.

In a more general model there may be a wide range within which the debt-income ratio can vary essentially freely in accordance with the shocks shown in equation (7), but there may be some eventual limits that come into play. A limit on the high side would arise when the debt-income ratio rises sufficiently to affect the probability of the government's default (n. 3 above). On the low side, public and private debts may become less perfect substitutes in terms of liquidity characteristics, etc., as the quantity of government bonds diminishes. The implied net worth aspect of public debt-corresponding to some monopoly power for the government in the sale of bonds-would then prescribe a target lower bound for the debt-income ratio. However, a zero value for $B$ does not constitute a necessary lower bound, even if the $B$ concept is limited to financial net worth (thereby not considering the value of governmentally owned real capital). There is nothing in the present analysis that rules out the possibility of the government's becoming a net creditor to the private sector. The last time this possibility arose for the federal government in the United States was in 1835 when the national debt was entirely paid off and the government sought desperately (!) for outlets for its surplus (Dewey 1931, p. 221). Apparently, the sharp contraction of 1837 solved this problem.

\section{Changes in Prices}

This section extends the model to allow for changes in the price level. Such changes enter the analysis because the government debt, which still takes the form of a one-period bond, is assumed to pay interest and principal in fixed nominal terms. Governmental finance through

${ }^{13}$ McCallum and Whitaker (in press) argue for automatic stabilizers as a device for stabilizing the economy in an environment where information on aggregate variables becomes available only with a lag. 
currency issue is not considered here, and any price changes that occur are treated as exogenous with respect to the division of governmental finance between debt and taxes. ${ }^{14}$ I first consider unanticipated price changes and then deal with anticipated inflation.

A one-time unexpected change in the price level can be modeled by allowing the current price level, $P_{1}$, to differ from $P_{0}$. Expectations of future price levels are assumed at this point to be static at $P_{1}$-that is, $P_{t}=P_{1}$ for all $t=1,2, \ldots$ Letting $B_{t}$ denote the stock of nominal debt outstanding at the end of period $t$, the government's budget constraint from equation ( 1 ) is now modified to

$$
G_{t}+r\left(B_{t-1} / P_{t}\right)=\tau_{t}+\left(B_{t}-B_{t-1}\right) / P_{t},
$$

where $G$ and $\tau$ are still in real terms, $r$ is still assumed to be constant, and $P_{t}=P_{1} \neq P_{0}$ for all $t=1, \ldots$ The entire analysis from before carries through in this case with the interpretation of the "real initial debt," $b_{0}$, as $B_{0} / P_{1}$. Accordingly, in equation (7), the dependent variable is now the growth rate of nominal debt, $\left(B_{1}-B_{0}\right) / B_{0}$. On the right-hand side the first variable becomes $P_{1}\left(G_{1}-\bar{G}_{1}\right) / B_{0}$, while the second now involves the term, $\left(P_{1} \bar{G}_{1}+r B_{0}\right) / B_{0}$. As the arbitrary length of the "period" becomes small, the difference in dating of the variables in these two expressions becomes unimportant. The principal result here is that one-time changes in the price level (or the current actual inflation rate in a continuous time setup) do not affect the change (growth rate) of the nominal debt. This conclusion should be somewhat surprising, since one-time changes in the price level do alter the ratio of (real) debt to (real) income. If the model determined a steady-state value of the debt-income ratio, a shift in the actual ratio would have temporary effects on the government deficit. These effects do not arise here because the model does not, in fact, determine this sort of steady-state ratio.

To model anticipated inflation, suppose now that prices are expected to change at the constant rate $\pi$-that is, $P_{t}=P_{0}(1+\pi)^{t}$. The nominal interest rate is given by $R \equiv r+\pi$. Although it is not crucial for present purposes, I assume that the real rate of interest, $r$, is invariant with inflation. ${ }^{15}$ The previous analysis of the choice of taxes over time goes through completely in terms of real variablesincluding $r$. The only amendment to the previous analysis is that the

\footnotetext{
${ }^{14}$ As with the invariance of the rate of return, this assumption would be valid as a first-order proposition if government bonds were not perceived as net wealth by the private sector.

${ }^{15}$ Some theoretical-basically indeterminate-analysis of this issue is surveyed in Barro and Fischer (1976, sec. 3). If interest payments are subject to tax at rate $\theta$, then the after-tax real rate of return is $\hat{r}=R(1-\theta)-\pi$. Independence of $\hat{r}$ from $\pi$ requires $R=(\hat{r}+\pi) /(1-\theta)$, so that $R$ would have to move more than one to one with $\pi$ in this circumstance.
} 
government budget constraint in equation $\left(1^{\prime}\right)$ must be modified to reflect the distinction between the nominal and real interest ratethat is, the new specification is

$$
G_{t}+R\left(B_{t-1} / P_{t}\right)=\tau_{t}+\left(B_{t}-B_{t-1}\right) / P_{t},
$$

where $R \equiv r+\pi$. With taxes already set at the value determined in the preceding analysis (where $\pi=0$ ), it follows that the "extra part" of current interest payments, $\pi\left(B_{t-1} / P_{t}\right)$, is financed entirely by extra issue of nominal debt. Equivalently, the growth rate of nominal debt, $\left(B_{t}-B_{t-1}\right) / B_{t-1}$, is raised by the amount $\pi$-an amount that is just sufficient to offset the expected effect of price changes on the real value of the outstanding stock of debt. Therefore, the incorporation of the anticipated inflation effect into equation (7) yields the revised expression for the growth rate of nominal debt,

$$
\begin{aligned}
\left(B_{1}-B_{0}\right) / B_{0}=[(1+\rho) /(1+r)]^{k} P_{1}\left(G_{1}-\bar{G}_{1}\right) / B_{0} \\
\quad-[(1+\rho) /(1+r)]^{n}\left[\left(P_{1} \bar{G}_{1}+r B_{0}\right) / B_{0}\right]\left[\left(Y_{1}-\bar{Y}_{1}\right) / \bar{Y}_{1}\right]+\rho+\pi .
\end{aligned}
$$

Accordingly, the nominal government debt grows, ceteris paribus, at the trend growth rate of nominal income, $\rho+\pi$. Note especially that it is the expected inflation rate, $\pi$, and not the actual rate that influences the growth rate of nominal debt. The effects of the transitory government expenditure and income variables in equation (8) are the same as those discussed above.

\section{Changes in the Rate of Return-Market versus Par Value of Government Debt}

Abstracting for convenience from price-level changes, suppose now that the current rate of return on the one-period government debt, $r$, differs from that applicable in the previous period, $r_{0}$. It is assumed that anticipated rates of return for future periods are still equal to the current rate, $r$. In the case of the one-period debt that is being considered, the government's budget condition of equation (1) is now modified to

$$
\begin{aligned}
& G_{1}+r_{0} b_{0}=\tau_{1}+\left(b_{1}-b_{0}\right), \\
& G_{t}+r b_{t-1}=\tau_{t}+\left(b_{t}-b_{t-1}\right), \quad t=2, \ldots,
\end{aligned}
$$

where the $b$ 's refer throughout to the real par (initial) value of debt. These conditions can be shown to imply that the overall budget constraint is altered from the form of equation (3) to

$$
\sum_{1}^{\infty}\left[G_{t} /(1+r)^{t}\right]+b_{0}\left(1+r_{0}\right) /(1+r)=\sum_{1}^{\infty}\left[\tau_{t} /(1+r)^{t}\right] .
$$


The budget constraint now involves the market value of the initial debt, $b_{0}^{*}=b_{0}\left(1+r_{0}\right) /(1+r)$, which is expressed as a present value at date 0 by means of the date 1 discount rate. Equation ( $\left.3^{\prime}\right)$ can be used to solve out for taxation over time, taking into account the constancy of the tax-income ratio in the optimal solution. The result is that the previous analysis goes through if all debt variables instead of being measured at par value are measured in terms of market value. Each market value is expressed as a present value at the corresponding date by means of the date 1 discount rate, $r$. (Note that the market value of debt at date $1, b_{1}^{*}$, is equal to $b_{1}$ for the case of one-period debt.) It is important to stress that the modified "deficit" variable that emerges from these calculations, $b_{1}^{*}-b_{0}^{*}$, is not the change in the market value of debt as it would customarily be measured, but rather the difference in market value with the current discount rate, $r$, used in the calculations for both date 1 and date 0 .

For the case of one-period, single-coupon debt, the solution can readily be expressed in terms of par values. Ignoring the temporary government expenditure and income variables and for the case where the trend growth rates of $G$ and $Y$ are equal (and where $\pi=0$ ), the result is

$$
\left(b_{1}-b_{0}\right) / b_{0}=\rho-\left(r-r_{0}\right)\left(\frac{1+\rho}{1+r}\right) .
$$

When $r$ exceeds $r_{0}$, the market value $b_{0}^{*}$ is below the par value $b_{0}$. Therefore, the achievement of a given change in the market value of debt requires a smaller value of $b_{1}$. Hence, the growth rate of debt measured at par value is related inversely to the change in the rate of return, $r-r_{0}$. Although the analysis is complicated by the inclusion of the temporary spending and income variables, it seems that this effect of the interest-rate change is the main new implication for the case of one-period debt.

In the empirically relevant situation where government debt exists with different maturity dates and various coupons, the main part of the analysis continues to go through. In particular, equation (3') still holds in terms of the market value of the initial debt $b_{0}^{*}$, again expressed as a present value at date 0 by means of the date 1 discount rate, $r$. However, the formula for $b *$ is substantially more complicated than that shown in equation ( $\left.3^{\prime}\right)$. It remains true that all previous results on debt issue apply with the debt variables measured in market-value terms-expressed as present values at the corresponding date with $r$ used as the discount rate. The difficulty arises in relating the market-value results, which involve complicated formulae for determining bond values, to the readily accessible figures on debt at par value. For the case of perpetual coupon bonds, where $b_{0}^{*}=$ 
$\left(r_{0} / r\right) b_{0}, b_{1}^{*}=b_{1}-b_{0}+\left(r_{0} / r\right) b_{0}$, with $r_{0}$ now interpreted as the average coupon rate on initially outstanding debt, the result in terms of par values is $\left(b_{1}-b_{0}\right) / b_{0}=\rho\left(r_{0} / r\right)$. The conclusion is again that an increase in $r$ above $r_{0}$ reduces the growth rate of debt when expressed in terms of par values. However, the effect now depends on a positive value of $\rho$, since the amount of debt (at par or market value) would remain constant if $\rho=0 .{ }^{16}$ Further, the relevant comparison is now between $r$ and an average of rates applying to the outstanding debt, and the ratio, $r_{0} / r$, appears instead of the difference, $r-r_{0}$.

It seems that in the general case $r$ would have to be compared with a complicated "average" value of past interest rates that took account of both quantities and maturities of the existing stock of debt. An additional complication arises in using par value figures when some portion of the debt is not issued at par. In any case the basic result from this section is that an increase in $r$ above the average of preceding rates would reduce the growth rate of debt when measured in terms of par values.

\section{Empirical Analysis}

An interesting way to test the theory would be to examine directly the hypothesis that the planned tax-income ratio was constant. Since changes in this ratio should then reflect only new information about the time path of government expenditures, etc., the theory has the implication that changes in tax rates should be unpredictable from knowledge of any lagged variables, including prior changes in rates. An approach for testing this type of hypothesis was developed for analogous propositions about consumption in Hall (1978). The approach has obvious analogues to tests of efficient-markets hypotheses. I plan to explore this research avenue at a later time, but the present empirical investigation is limited to hypotheses and tests that directly concern public debt movements.

\section{Setup of the Analysis}

The form of the systematic part of the empirical equation to be applied to annual observations is derived from equation (8) as

$$
\begin{aligned}
\log \left(B_{t} / B_{t-1}\right)=\alpha_{0}+\alpha_{1} \pi_{t}+\alpha_{2}[ & \left.P_{t}\left(G_{t}-\bar{G}_{t}\right) / \bar{B}_{t}\right] \\
& -\alpha_{3}\left[\log \left(Y_{t} / \bar{Y}_{t}\right)\left(P_{t} \bar{G}_{t}+r \bar{B}_{t}\right) / \bar{B}_{t}\right],
\end{aligned}
$$

\footnotetext{
${ }^{16}$ Some effects would arise from the temporary government spending and income variables even when $\rho=0$.
} 
where $B_{t}$ is the stock of nominal debt at the end of calendar year $t, \bar{B}_{t}$ is the average amount of debt outstanding during year $t, \pi_{t}$ is the average anticipated rate of inflation during year $t, P_{t}$ is the average price level for year $t, G_{t}$ is real federal government expenditure (aside from interest payments) during year $t, Y$, is aggregate real income (GNP) for year $t$, and $\bar{Y}_{t}$ is the level of normal income during year $t$. From the perspective of equation (8), the assumption that the $\alpha$ coefficients in equation (10) are constant amounts to neglecting variations in the growth rate $\rho$, real interest rate $r$, and the durations of temporary government expenditure and income $(k$ and $n)$. The theory has the following implications for the coefficients. (1) $\alpha_{0}$ : This coefficient would equal the growth rate, $\rho$, if real income and government expenditure grow at the same rate. However, if government expenditures are expected to grow faster than income for some period, there would be a downward effect on the constant as indicated in a general way from the $(\rho-\gamma)$ term in equation (5). ${ }^{17}$ (2) $\alpha_{1}$ : This coefficient should equal unity-the anticipated rate of inflation has a one-to-one effect on the growth rate of nominal debt. (3) $\alpha_{2}$ : This coefficient corresponds to $[(1+\rho) /(1+r)]^{k}$ in equation (8), which is below but close to unity. An interval of something like $(0.8,1.0)$ would appear to be a reasonable implication of the theory. (4) $\alpha_{3}$ : This coefficient corresponds to $[(1+\rho) /(1+r)]^{n}$ in equation (8), which is also below but close to unity. Again, an interval of something like $(0.8$, 1.0) appears reasonable.

The model implies also that certain variables would be irrelevant for the growth rate of public debt. In particular, the level of the outstanding stock of debt-relative, say, to the trend value of income-is excluded from equation (8). This proposition is tested by adding the variable, $B_{t-1} /\left(P_{t-1} \bar{Y}_{t-1}\right)-$ the previous year's ratio of real debt to normal real income-to the estimating equation. The theory also stresses the role of temporary government expenditure rather than the level of spending. (See, however, n. 17 above for a possible effect of the level.) Hence, the effect of a variable like $P_{t} \bar{G}_{t} / \bar{B}_{t}$-normal government spending relative to the stock of debt-is worth examining.

\section{Measures of Variables}

The present analysis considers evidence on the determination of public debt in the United States since 1917. I hope to extend the investigation to earlier dates but have encountered some data prob-

\footnotetext{
${ }^{17}$ An additional variable, $P_{t} \bar{G}_{t} / \bar{B}_{t}$, could be added to eq. (10) to pick up this effect. However, this variable is not significant in any of the empirical analysis (see below).
} 
lems. One minor difficulty is that the available public debt data before 1916 refer to fiscal years, whereas the rest of the analysis is on a calendar-year basis. A more serious problem arises in the measurement of anticipated inflation (see below), which causes difficulties even for the post-1916 period.

The quantity of nominal debt, $B$, is measured as the outstanding stock of interest-bearing federal debt at par value in the hands of the "public" at the end of each calendar year. ${ }^{18}$ In particular, the figures net out holdings of debt by the Federal Reserve, Social Security Administration, etc. I have not carried out the computations that would be required to adjust the par value measures for changes in rates of return, as discussed above. (Note that a market-value series, even if it were available, would not be the appropriate construct for present purposes.) The earlier analysis suggests that a change-ininterest-rate variable should then be added to equation (10). However, a proper measure of this variable would entail the construction of an appropriate average coupon rate on outstanding debt. Since this variable has not yet been constructed, I have limited consideration to the variable, $R G_{t}-R G_{t-1}$, where $R G$ is an index of the interest rate on government bonds. Although there is a hint in the empirical results that this variable enters in the hypothesized manner, it turns out to be statistically insignificant and quantitatively unimportant. I am uncertain whether refinement of the measurement of this variable would materially affect the results.

The $\bar{B}_{t}$ variable, which scales the values of $B-\bar{G}$ and $\log (Y-\bar{Y})$ in equation (10), is measured as $\sqrt{B_{t} \cdot B_{t-1}}$. Since this construction introduces $B_{t}$ into the right-hand side of equation (10), I have carried out the estimation using as instruments the values of the $G-\bar{G}$ and $\log (\bar{Y} / \bar{Y})$ variables with $B_{t-1}$ used instead of $\bar{B}_{t}$ as a scaling factor. It turns out that ordinary least-squares estimates differ negligibly from these instrumental estimates.

\footnotetext{
${ }^{18}$ See the notes to table 3 below for details on the public debt variable. The definition includes fully guaranteed securities that were issued by some New Deal agencies. These amounts are significant for 1934-44. Debt held by federal agencies and trust funds (but not by federally sponsored private corporations) and the Federal Reserve have been netted out. Non-interest-bearing components of government debt are excluded throughout. No adjustments have been made for government acquisitions of real capital or claims on the private sector or foreigners. Governmental "liability" for future social security benefits or other payments has not been included in the definition of public debt. It seems that expected future social security benefits and governmental acquisitions of capital, etc., would enter the present analysis as they affected the anticipated future value of federal expenditures or receipts. E.g., the anticipation of rapid growth in an expenditure component, such as social security benefits, would enter the analysis as indicated in $\mathrm{n} .11$ above. Expenditures on large capital projects, which are likely to represent a blip in spending, would tend to be mostly deficit financed.
} 
For the 1948-76 period I have constructed an expected rate-ofinflation variable, $\pi$, based on the estimated equation for the GNP deflator in an earlier study of mine (1978). This variable, which refers to the expected rate of change of the GNP deflator over a 1-year horizon, is tabulated in table 1 and is discussed in detail in the notes to that table. I do not presently have an analysis of price determination before 1948 to use for the construction of the $\pi$-variable. (The World War II price controls cause difficulty for the years immediately prior to 1948.) For the 1948-76 period it turns out that a long-term interest-rate variable proxies satisfactorily for $\pi$. Specifically, the estimated after-tax nominal rate on corporate bonds, $R(1-\theta)$, where $\theta$ is an estimate of the tax rate, ${ }^{19}$ would measure the anticipated rate of inflation (up to a constant) over the average period of the bonds if the anticipated after-tax real rate of return were fixed. ${ }^{20}$ This interest-rate variable is available also for the pre-1948 period, but the assumption of a constant anticipated real rate of return over the entire 1917-76 sample is doubtful. Specifically, the nominal yields (see table 1) relative to actual price changes during the interwar period are much higher than those since 1941. The likely anticipated deflation after World War I is, in particular, not captured by the interest-rate variable for 1919-21. I have presently used the $R(1-\theta)$ variable for the 1922-76 sample but have included a dummy variable for the 1922-40 years to allow for a different (presumably higher) anticipated real rate of return over that period. I have not included the 1917-21 years in the main analysis, although extrapolations of the estimates to those years are examined. The present procedure for measuring $\pi$ before 1948 is obviously not satisfactory, and I hope to construct a more appropriate variable, especially for the planned extension of the analysis to the pre-World War I period. ${ }^{21}$

I have based my measurement of normal real federal expenditure, $\bar{G}$, on the variable that worked satisfactorily in my previous studies of

${ }^{19}$ I have calculated this rate as the ratio of federal plus state and local personal income tax payments to personal income, although this measure may underestimate the average marginal rate for bondholders.

${ }^{20}$ Replacing $R(1-\theta)$ by $R$ produces a negligible change in the results. The government bond rate, $R G$, yields basically similar results. A short-term interest-rate variable-specifically, that on prime commercial paper-was insignificant when used instead of a long-term rate as a proxy for $\pi$ in the government debt equation. A likely interpretation is that variations in anticipated real rates of return are important in the short-term rate.

${ }^{21}$ I have not attempted to calculate the $\pi$ variable as a distributed lag of actual rates of price change. That type of relation would seem much different over a gold standard regime (1880-1914 and, to a lesser extent, 1919-33) as compared with a fiat money regime. The distributed lag of inflation approach fails especially in episodes like 1919-21, where experience appears to be dominated by a return to normal levels of prices rather than a continuation of past rates of price change. 
TABLE 1

Values of INDEPENDENT Variables

\begin{tabular}{|c|c|c|c|c|c|c|c|}
\hline & $\pi$ & $R(1-\theta)$ & $\begin{array}{c}\log \\
(Y / \bar{Y})\end{array}$ & $P \bar{G} / \bar{B}$ & $P(G-\bar{G}) / \bar{B}$ & $\frac{P \bar{G} \cdot \log (Y / \bar{Y})}{\bar{B}}$ & $G / \bar{Y}$ \\
\hline 1916 & $\ldots$ & .045 & -.051 & & & & .016 \\
\hline 1917 & $\ldots$ & .045 & -070 & .75 & 1.908 & -.052 & .102 \\
\hline 1918 & $\ldots$ & .054 & .021 & .29 & 1.218 & .006 & .230 \\
\hline 1919 & $\ldots$ & .054 & -.040 & .21 & .312 & -.009 & .142 \\
\hline 1920 & $\ldots$ & .060 & -.110 & .24 & -.021 & -.026 & .053 \\
\hline 1921 & $\ldots$ & .059 & -.226 & .21 & -.022 & -.049 & .052 \\
\hline 1922 & $\ldots$ & .050 & -.104 & .21 & -.060 & -.021 & .039 \\
\hline 1923 & $\ldots$ & .051 & -.015 & .21 & -.061 & -.003 & .037 \\
\hline 1924 & $\ldots$ & .050 & -.042 & .21 & -.063 & -.009 & .034 \\
\hline 1925 & $\ldots$ & .048 & .013 & .22 & -.059 & .003 & .034 \\
\hline 1926 & $\ldots$ & .047 & .050 & .22 & -.062 & .011 & .033 \\
\hline 1927 & $\ldots$ & .045 & .020 & .23 & -.059 & .005 & .032 \\
\hline 1928 & $\ldots$ & .045 & .000 & .25 & -.053 & .000 & .033 \\
\hline 1929 & $\ldots$ & .047 & .040 & .25 & -.084 & .010 & .026 \\
\hline 1930 & $\ldots$ & .045 & -.084 & .25 & -.061 & -.021 & .028 \\
\hline 1931 & $\ldots$ & .045 & -.189 & .24 & .034 & -.045 & .046 \\
\hline 1932 & $\ldots$ & .050 & -.363 & .20 & -.013 & -.073 & .038 \\
\hline 1933 & $\ldots$ & .044 & -.409 & .18 & .018 & -.075 & .048 \\
\hline 1934 & $\ldots$ & .040 & -.359 & .19 & .081 & -.070 & .068 \\
\hline 1935 & $\ldots$ & .036 & -.298 & .18 & .050 & -.055 & .067 \\
\hline 1936 & $\ldots$ & .032 & -.196 & .19 & .086 & -.037 & .087 \\
\hline 1937 & $\ldots$ & .032 & -.176 & .20 & .019 & -.035 & .068 \\
\hline 1938 & $\ldots$ & .031 & -.243 & .21 & .037 & -.050 & .079 \\
\hline 1939 & $\ldots$ & .030 & -.195 & .21 & .028 & -.041 & .081 \\
\hline 1940 & $\ldots$ & .028 & -.148 & .22 & .032 & -.032 & .086 \\
\hline 1941 & $\ldots$ & .027 & -.029 & .24 & 192 & -.007 & .159 \\
\hline 1942 & $\ldots$ & .027 & .082 & .26 & .536 & .021 & .385 \\
\hline 1943 & $\ldots$ & .024 & .206 & .23 & .503 & .048 & .549 \\
\hline 1944 & $\ldots$ & .024 & .253 & .23 & .350 & .057 & .585 \\
\hline 1945 & $\ldots$ & .023 & .214 & .22 & .179 & .048 & .493 \\
\hline 1946 & $\cdots$ & .023 & .033 & .23 & -.070 & .008 & .175 \\
\hline 1947 & & .023 & -.022 & .26 & -.110 & -.006 & .125 \\
\hline 1948 & -.002 & .026 & -.017 & .27 & -.092 & -.004 & .133 \\
\hline 1949 & -.002 & .025 & -.046 & .27 & -.057 & -.012 & .153 \\
\hline 1950 & .002 & .024 & .002 & .27 & -.060 & .001 & .143 \\
\hline 1951 & .022 & .026 & .044 & .30 & -.007 & .013 & .187 \\
\hline 1952 & .027 & .026 & .046 & .33 & .029 & .016 & .215 \\
\hline 1953 & .038 & .028 & .049 & .36 & .029 & .018 & .221 \\
\hline 954 & .019 & .026 & .001 & .37 & -.020 & .000 & .191 \\
\hline 1955 & .024 & .027 & .030 & .38 & -.048 & .011 & .176 \\
\hline 1956 & .015 & .030 & .016 & .41 & -.052 & .007 & .174 \\
\hline 1957 & .010 & .035 & -.002 & .45 & -.043 & -.001 & .180 \\
\hline 1958 & .010 & .034 & -.039 & :47 & -.026 & -.018 & .190 \\
\hline 1959 & .019 & .039 & -.016 & .48 & -.039 & -.008 & .184 \\
\hline 1960 & .020 & .039 & -.029 & .50 & -.051 & -.014 & .179 \\
\hline 1961 & .013 & .039 & -.039 & .52 & -.034 & -.021 & .187 \\
\hline 1962 & .022 & .038 & -.019 & .54 & -.024 & -.010 & .192 \\
\hline 1963 & .009 & .038 & -.015 & .57 & -.037 & -.009 & .189 \\
\hline 1964 & .014 & .040 & .001 & .59 & -.046 & .000 & .186 \\
\hline 1965 & .018 & .040 & .023 & .62 & -.053 & .014 & .184 \\
\hline
\end{tabular}


TABLE 1 (Continued)

\begin{tabular}{lccccccc}
\hline \hline & & & & & & \multicolumn{3}{c}{$P \bar{G} \cdot \log (Y / \bar{Y})$} \\
& & & & $\log$ & & & \\
& & $R(1-\theta)$ & $(Y / \bar{Y})$ & $P \bar{G} / \bar{B}$ & $P(G-\bar{G}) / \bar{B}$ & $\bar{B}$ & $G / \bar{Y}$ \\
\hline 1966 & .026 & .046 & .045 & .68 & -.011 & .030 & .199 \\
1967 & .030 & .049 & .036 & .74 & .015 & .027 & .213 \\
1968 & .029 & .054 & .044 & .80 & .015 & .035 & .217 \\
1969 & .035 & .061 & .034 & .87 & -.029 & .030 & .208 \\
1970 & .041 & .070 & -.005 & .96 & -.047 & -.005 & .207 \\
1971 & .050 & .065 & -.011 & .99 & -.058 & -.011 & .205 \\
1972 & .062 & .063 & .010 & 1.00 & -.034 & .010 & .211 \\
1973 & .061 & .065 & .027 & 1.07 & -.055 & .029 & .220 \\
1974 & .061 & .075 & -.025 & 1.21 & -.078 & -.030 & .207 \\
1975 & .060 & .078 & -.079 & 1.20 & -.032 & -.095 & .218 \\
1976 & .062 & .074 & -.055 & 1.08 & -.044 & -.059 & .217 \\
\hline
\end{tabular}

NOTE. $-\pi_{t} \equiv \log \left(P_{t+1}\right)-\log \left(P_{t}\right)$, where $\log \left(P_{t+1}\right)$ and $\log \left(P_{t}\right)$ are predicted and estimated values, respectively, of the GNP deflator from the equation in Barro (1978, eq. 13). These calculations are based on lagged values of money growth and the unemployment rate and on contemporaneous values of the interest rate and federal spending. $R$ from 1919 is Moody's Aaa index of corporate bond rates and for 1916-18 is the average of Durand's yield on 10-and 20-year bonds, adjusted by +.0048 to conform with the overlap for 1919-21 (U.S. Council of Economic Advisers 1977, p. 260; U.S. Bureau of the Census 1975, pp. 1003-4). $\theta$ is the ratio of federal plus state and local personal income tax payments to personal income (U.S. Council of Economic Advisers 1977, p. 210; U.S. Department of Commerce 1976, pp. 97, 108, 334, 340-41, July 1977, pp. 31,32, and 1973, p. 188; U.S. Bureau of the Census 1975, p. 1107). $Y$ is real GNP (1972 base) and $P$ is the GNP deflator $(1972=1.0)$ from U.S. Council of Economic Advisers (1977, pp. 188, 190); U.S. Department of Commerce (1976, pp. 324, 349). Figures before 1929 are based on data from ibid. 1973, series A1, p. 182 and series B61, p. 222. $\log (Y)$ is a trend value of real GNP, calculated as 1946-76: $2.985+.0354 \cdot t, 1915-45: 3.912+.0250 \cdot t, 1880-1914: 3.291+.0359 \cdot t$, where $t$ is time with $1858=1 . G$ is nominal total federal expenditure divided by the GNP deflator. Expenditure data are from U.S. Council of Economic Advisers (1977, p. 270). Data before 1929 are from Firestone $(1960$, table $A-3) \cdot \bar{B}_{t} \equiv \sqrt{B_{t} \cdot B_{t-1}}$.

money growth $(1977,1978)$. This variable is a distributed lag of total real federal spending using an adaptation coefficient of 0.2 per year. The variable has been modified here to take account of the long-term growth rate of real federal spending, which is estimated as 5.6 percent per year-the average growth rate from 1860 to 1976. Presumably, this measurement could be improved by relating the concept of normal spending to the actual time-series behavior of the federal spending series. Another problem is that the variable includes government interest payments as a part of government expenditure. This inclusion would be unimportant for the calculation of $G-\bar{G}$ in equation (10) but would have some effect on the last term in the equation, which involves the expression, $P \bar{G}+r \bar{B}$. Essentially, it is only the real interest rate part of government interest payments that should be included as a part of real government expenditure (see above). The portion of interest payments, $\pi \bar{B}$, that reflects anticipated inflation corresponds also to finance by issue of nominal debt at rate $\pi$. These payments play no role in influencing taxes, etc., and should be excluded from the term in equation (10). Since I believe this consideration to be quantitatively unimportant in terms of the manner it enters 
into equation (10), I have not attempted to adjust government expenditure by eliminating a portion of interest payments.

The departure of income from normal, $\log (Y / \bar{Y})$, is calculated for the 1946-76 period from my previous (1978) analysis of output (real GNP). $\log \left(\vec{Y}_{t}\right)$ is calculated along the trend line, with a growth rate of 3.54 percent per year, that is implied by that analysis. I have also calculated a pure trend relation for real GNP over the 1880-1914 period, which reveals a strikingly similar growth rate of 3.59 percent per year. From 1915 to 1945 (for lack of a better procedure), I connected the fitted trend values for real GNP from 1914 and 1946 along a constant growth line, which implied an average growth rate of 2.50 percent per year. ${ }^{22}$ The values of $\log (Y / \bar{Y})$ are indicated, along with the values of the $P \bar{G} \cdot \log (Y / \bar{Y})$ variable, in table 1 .

Finally, the $P$ variable is measured by the average value of the GNP deflator for the year.

\section{Empirical Results}

Table 2 describes the estimates of equation (10) for various sample periods. Although there is an indication that the error variance during World War II (1941-47 sample) exceeds that before 1941 (1922-40), which exceeds that of the recent period (1948-76), I have presently dealt only with unweighted regressions. The DurbinWatson statistics suggest absence of serial correlation in the residuals. Further, if a lagged dependent variable, $D B_{t-1}$, is added to the equation its estimated coefficient differs insignificantly from zero over all sample periods.

Estimates are shown in table 2 with the coefficient of the expected inflation variable ( $\pi$ for $1948-76$ or the $R[1-\theta]$ variable for all sample periods) unrestricted and with this coefficient restricted to equal unity. The unrestricted estimates of this coefficient differ insignificantly from one at the 5 percent level in all cases. For example, for the 1948-76 period the estimated $\pi$-coefficient is $1.12, \mathrm{SE}=0.22$; while that on $R(1-\theta)$ is $1.32, \mathrm{SE}=0.25$. A comparison of results based on the $\pi$ and $R(1-\theta)$ variables for this sample suggests that the interest-rate variable is a satisfactory proxy for anticipated inflation. However, as noted above, this outcome for the post-1948 period does not guarantee the appropriateness of the interest-rate variable for earlier years. For the 1922-76 sample the estimate of the $R(1-\theta)$ coefficient is $1.44, \mathrm{SE}=0.28$, while that for the 1922-40, 1948-76 sample is 1.31, $\mathrm{SE}=0.27$. Again, these estimates do not differ

\footnotetext{
22In other words, although the post-World War II growth rate of output coincides with that from 1880-1914, the position of real GNP implied by the 1880-1914 trend line has not been reattained after the Great Depression and World War II.
} 


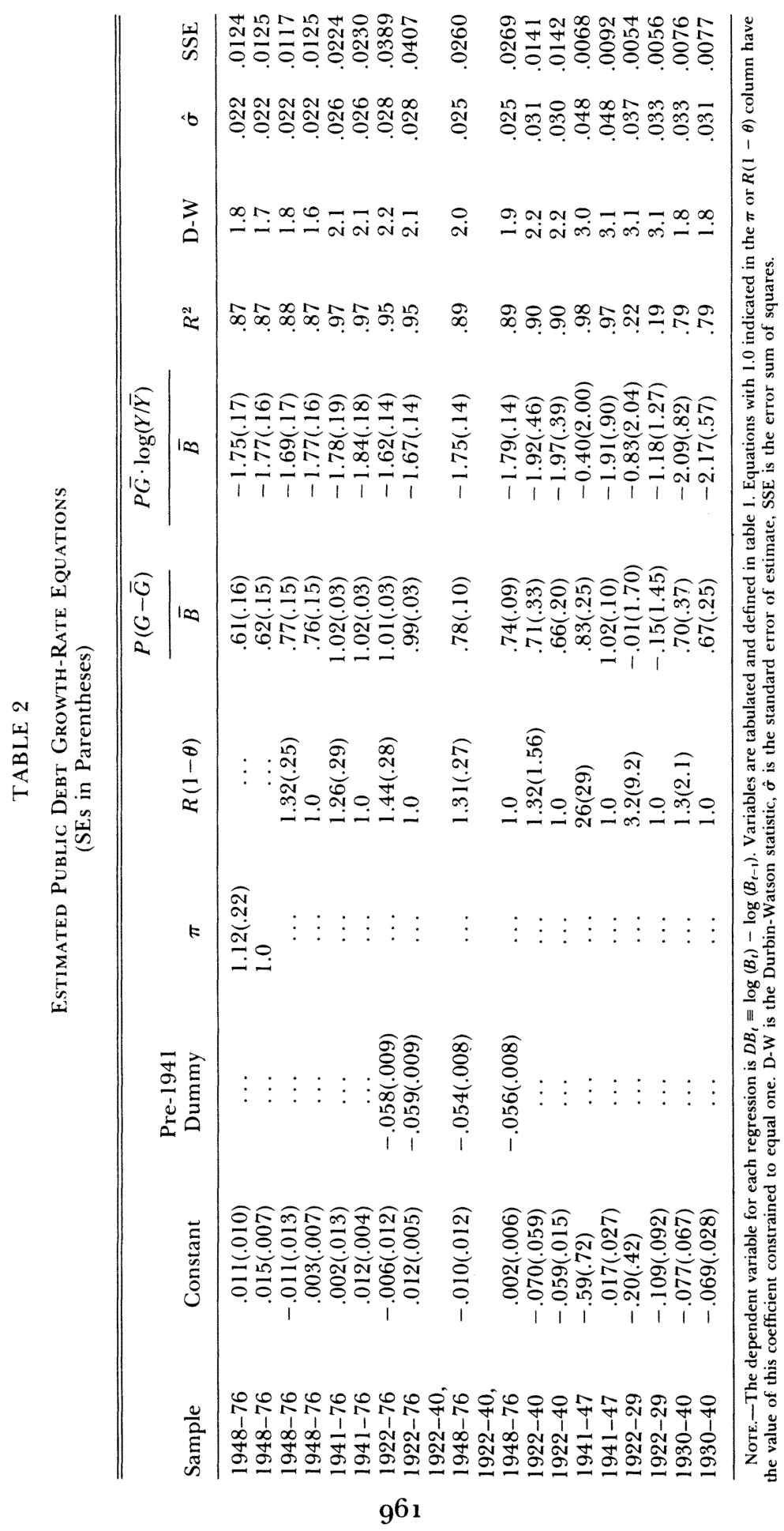


significantly from one at the 5 percent level. Since the theoretical value of unity is in accord with these results, and since an (appropriate) restriction of this coefficient would sharpen the remaining analysis, I focus the subsequent discussion on the restricted form of the government debt equation.

The 1922-76 and 1922-40, 1948-76 samples indicate a significantly negative coefficient for a pre-1941 dummy variable with a magnitude of $0.05-0.06$ per year. From the perspective of the $R(1-$ $\theta)$ variable as an expected inflation-rate proxy, the interpretation would be that the average anticipated (after-tax) real rate of return before 1941 was higher by $0.05-0.06$ per year than that after 1941 . Clearly, the interpretation could also be that other factors reduced the average growth rate of nominal debt before 1941 by $0.05-0.06$ per year (or by some part of that amount) below that of the post-1941 period. Without a direct measure of anticipated inflation it is not possible to compare the constant term before 1941 with that of the later years. However, this difficulty does not prevent a comparison of the other coefficients across the different samples.

With the inclusion of the pre-1941 dummy variable, the hypothesis of a stable set of coefficients across the various sample periods is accepted. That is, the empirical evidence is in accord with a single set of coefficients for the temporary government expenditure and income variables. The following $F$-tests (with 5 percent critical values shown in parentheses) ${ }^{23}$ arise for tests of the common coefficient hypothesis for the indicated samples and for cases where the coefficient of the $R(1-\theta)$ variable is restricted to equal unity. (The results are similar in cases where the $R(1-\theta)$ coefficient is unrestricted.)

$$
\begin{array}{lll}
1941-47 ; 1948-76: & F_{30}^{3}=0.6 & (2.9), \\
1922-40 ; 1948-76: & F_{42}^{2}=0.0 & (3.2), \\
1922-40 ; 1941-47 ; 1948-76: & F_{46}^{5}=1.2 & (2.4), \\
1922-29 ; 1930-40: & F_{13}^{3}=0.3 & (3.4) .
\end{array}
$$

Hence, the results are consistent with the hypothesis that the response of government debt to temporary movements in government spending or in aggregate income has been stable since 1922. The results are also consistent with a single constant over the 1922-29 and 1930-40 subsamples and over the 1941-47 and 1948-76 subsamples.

For the case where the $R(1-\theta)$ variable is employed with a coefficient restricted to unity and for the 1922-40, 1948-76 sample, the estimated coefficient of the temporary federal spending variable,

\footnotetext{
${ }^{23}$ Heteroscedasticity across the different subperiods would have some effect on these $F$-values.
} 
$P(G-\bar{G}) / \bar{B}$, is $0.78, \mathrm{SE}=0.10$. Over the World War II sample, 1941-47, the estimated coefficient is $1.02, \mathrm{SE}=0.10$, which dominates the overall sample (1922-76) estimate, $1.01, \mathrm{SE}=0.03$. These estimates are in accord with the underlying hypothesis of a coefficient in an interval of roughly $(0.8,1.0)$. A lagged value of the $G-\bar{G}$ variable is insignificant when added to the debt equation.

It is worth noting from table 1 that the constructed $G-\bar{G}$ variable, which incorporates a trend growth rate of 5.6 percent per year, is negative except for wartime years (1917-19, 1941-45, 1952-53, 1967-68) and the period of rapid government expansion during the Great Depression (1931 and 1933-40). The temporary government spending variable can average to zero, ex ante, only if expenditure bulges associated with large wars are offset by a much larger number of years with small negative values. Hence, the typical peacetime value (1920-30 and 1946-76 except for 1952-53 and 1967-68 in the present sample) shows a negative value of the $G-\bar{G}$ variable, which produces a declining, rather than a constant, debt-income ratio as the normal peacetime pattern. In this respect the ratio of debt to normal income, as shown in table 3 , declined from a peak value of 0.29 in 1919 to a trough of 0.15 in 1930 (before rising during the Depression), and declined from a peak value of 1.33 in 1945 to a trough of 0.19 in 1974 (before rising slightly to 0.23 in 1976). The basic pattern of peacetime decline in the debt-income ratio appears similar after the two world wars, although the starting ratio is much lower in 1919 than in 1945, and the period following World War I contains a much smaller number of non-Depression, peacetime years than that following World War II. The period following the Civil War seems to exhibit the same general pattern as that following the two world wars. The peak debt-nominal income ratio (based on June figures for the public debt) was about 0.25 in 1866 and declined from there over a long, almost entirely peacetime period to a trough of 0.02 in 1916 . The $G-\bar{G}$ variable, as measured in the present analysis, would be negative throughout the 1866-1916 period except for a small positive value in 1892 and for the years of the Spanish-American War, 1898-99.

The estimated coefficient of the temporary income variable, log $(Y / \bar{Y}) \cdot P \bar{G} / \bar{B}$, over the $1922-76$ sample is $-1.67, \mathrm{SE}=0.14$. (A lagged value of this variable is insignificant if added to the equation.) The estimated coefficient of the $\log (Y / \bar{Y})$ variable significantly exceeds in magnitude the value, 1.0, that appears as the upper limit of the ex ante interval on this coefficient. Hence, there is an indication that the magnitude of typical countercyclical debt response has exceeded the amount that would be dictated purely from efficient public finance considerations. There is, however, no indication that this 
TABLE 3

Actual and Estimated Values of Public Debt

\begin{tabular}{|c|c|c|c|c|c|c|c|}
\hline & \multirow[b]{2}{*}{$\begin{array}{r}D B \\
(1)\end{array}$} & \multicolumn{2}{|c|}{$\begin{array}{c}1922-76 \text { Equation, } \\
R(1-\theta) \text { CoEfFicient }=1\end{array}$} & \multicolumn{2}{|c|}{$\begin{array}{c}\text { 1948-76 EQUATION, } \\
\pi \text {-CoEFFICIENT }=1\end{array}$} & \multirow[b]{2}{*}{$\begin{array}{l}B \\
(6)\end{array}$} & \multirow[b]{2}{*}{$\begin{array}{l}B /(\bar{Y} \cdot P) \\
\quad(7)\end{array}$} \\
\hline & & $\begin{array}{l}\hat{D B} \dot{B} \\
(2)\end{array}$ & $\begin{array}{c}D B R \\
(3)\end{array}$ & $\begin{array}{r}T \\
(4)\end{array}$ & $\begin{array}{c}D B R \\
(5)\end{array}$ & & \\
\hline 1916 & $\cdots$ & & $\ldots$ & $\ldots$ & $\ldots$ & .91 & .02 \\
\hline 1917 & 2.040 & $(1.976)$ & $(.065)$ & $\ldots$ & $\ldots$ & 7.0 & .11 \\
\hline 1918 & 1.075 & (1.203) & $(-1.29)$ & $\ldots$ & $\ldots$ & 20.5 & .26 \\
\hline 1919 & .166 & $(.331)$ & $(-.165)$ & $\ldots$ & $\ldots$ & 24.2 & .29 \\
\hline 1920 & -.038 & $(.036)$ & $(-.074)$ & $\ldots$ & $\ldots$ & 23.3 & .24 \\
\hline 1921 & -.039 & $(.071)$ & $(-.110)$ & $\ldots$ & $\ldots$ & 22.4 & .27 \\
\hline 1922 & -.036 & -.020 & -.017 & $\ldots$ & $\ldots$ & 21.6 & .26 \\
\hline 1923 & -.038 & -.051 & .014 & $\ldots$ & $\ldots$ & 20.8 & .24 \\
\hline 1924 & -.049 & -.045 & -.004 & $\ldots$ & $\ldots$ & 19.8 & .23 \\
\hline 1925 & .000 & -.062 & .062 & $\ldots$ & $\ldots$ & 19.8 & .22 \\
\hline 1926 & -.112 & -.080 & -.032 & $\ldots$ & $\ldots$ & 17.7 & .19 \\
\hline 1927 & -.064 & -.067 & .003 & $\ldots$ & $\ldots$ & 16.6 & .18 \\
\hline 1928 & -.049 & -.054 & .005 & $\ldots$ & $\ldots$ & 15.8 & .16 \\
\hline 1929 & -.059 & -.101 & .042 & $\ldots$ & $\ldots$ & 14.9 & .15 \\
\hline 1930 & -.007 & -.027 & .020 & $\ldots$ & $\ldots$ & 14.8 & .15 \\
\hline 1931 & .084 & .107 & -.023 & $\ldots$ & $\ldots$ & 16.1 & .18 \\
\hline 1932 & .123 & .111 & .012 & $\ldots$ & $\ldots$ & 18.2 & .22 \\
\hline 1933 & .162 & .142 & .020 & $\ldots$ & $\ldots$ & 21.4 & .26 \\
\hline 1934 & .167 & .189 & -.022 & $\ldots$ & $\ldots$ & 25.3 & .27 \\
\hline 1935 & .177 & .131 & .046 & $\ldots$ & $\ldots$ & 30.2 & .31 \\
\hline 1936 & .104 & .132 & -.028 & $\ldots$ & $\ldots$ & 33.5 & .33 \\
\hline 1937 & .029 & .062 & -.033 & $\ldots$ & $\ldots$ & 34.5 & .32 \\
\hline 1938 & .043 & .105 & -.062 & $\ldots$ & $\ldots$ & 36.0 & .33 \\
\hline 1939 & .070 & .079 & -.009 & $\ldots$ & $\ldots$ & 38.6 & .35 \\
\hline 1940 & .072 & .066 & .006 & $\ldots$ & $\ldots$ & 41.5 & .36 \\
\hline 1941 & .245 & .242 & .003 & $\ldots$ & $\ldots$ & 53.0 & .41 \\
\hline 1942 & .583 & .536 & .047 & $\ldots$ & $\ldots$ & 94.9 & .65 \\
\hline 1943 & .407 & .454 & -.047 & $\ldots$ & $\ldots$ & 142.6 & .91 \\
\hline 1944 & .301 & .288 & .012 & $\ldots$ & $\ldots$ & 192.6 & 1.18 \\
\hline 1945 & .170 & .133 & .036 & $\ldots$ & $\ldots$ & 228.2 & 1.33 \\
\hline 1946 & -.097 & -.047 & -.050 & $\ldots$ & $\ldots$ & 207.2 & 1.02 \\
\hline 1947 & -.030 & -.064 & .034 & $\ldots$ & $\ldots$ & 201.0 & .84 \\
\hline 1948 & -.038 & -.046 & .008 & -.037 & -.001 & 193.6 & .74 \\
\hline 1949 & .035 & .001 & .034 & -.001 & .035 & 200.4 & .74 \\
\hline 1950 & -.014 & -.024 & .010 & -.021 & .007 & 197.6 & .69 \\
\hline 1951 & -.018 & .008 & -.027 & .009 & -.027 & 194.0 & .61 \\
\hline 1952 & .019 & .041 & -.022 & .033 & -.014 & 197.7 & .60 \\
\hline 1953 & .019 & .040 & -.021 & .040 & -.021 & 201.5 & .58 \\
\hline 1954 & .013 & .012 & .001 & .017 & -.004 & 204.1 & .56 \\
\hline 1955 & .000 & -.027 & .026 & -.011 & .011 & 204.0 & .53 \\
\hline 1956 & -.029 & -.020 & -.010 & -.013 & -.016 & 198.1 & .48 \\
\hline 1957 & -.001 & .006 & -.017 & .000 & -.011 & 195.9 & .44 \\
\hline 1958 & .033 & .051 & -.019 & .041 & -.009 & 202.4 & .43 \\
\hline 1959 & .035 & .025 & .009 & .024 & .011 & 209.6 & .42 \\
\hline 1960 & -.014 & .025 & -.039 & .029 & -.043 & 206.6 & .40 \\
\hline 1961 & .022 & .052 & -.029 & .044 & -.021 & 211.3 & .39 \\
\hline 1962 & .018 & .044 & -.026 & .040 & -.021 & 215.2 & .37 \\
\hline 1963 & .006 & .028 & -.022 & .016 & -.011 & 216.4 & .36 \\
\hline 1964 & .008 & .006 & .002 & -.001 & .008 & 218.1 & .34 \\
\hline
\end{tabular}


TABLE 3 (Continued)

\begin{tabular}{|c|c|c|c|c|c|c|c|}
\hline & \multirow[b]{2}{*}{$\begin{array}{l}D B \\
(1)\end{array}$} & \multicolumn{2}{|c|}{$\begin{array}{c}1922-76 \text { EQuation, } \\
R(1-\theta) \text { Coefficient }=1\end{array}$} & \multicolumn{2}{|c|}{$\begin{array}{c}1948-76 \text { EQUATION } \\
\pi \text {-COEFFICIENT }=1\end{array}$} & \multirow[b]{2}{*}{$\begin{array}{l}B \\
(6)\end{array}$} & \multirow[b]{2}{*}{$\begin{array}{c}B /(\bar{Y} \cdot P) \\
\quad(7)\end{array}$} \\
\hline & & $\begin{array}{l}\hat{D B} \\
(2)\end{array}$ & $\begin{array}{c}D B R \\
(3)\end{array}$ & $\begin{array}{l}\hat{D B} \\
(4)\end{array}$ & $\begin{array}{c}D B R \\
(5)\end{array}$ & & \\
\hline 1965 & -.009 & -.023 & .014 & -.025 & .016 & 216.1 & .32 \\
\hline 1966 & -.006 & -.004 & -.001 & -.021 & .015 & 214.9 & .30 \\
\hline 1967 & .018 & .031 & -.013 & .006 & .012 & 218.9 & .29 \\
\hline 1968 & .030 & .023 & .007 & -.009 & .039 & 225.6 & .27 \\
\hline 1969 & -.025 & -.005 & -.020 & -.021 & -.004 & 220.0 & .24 \\
\hline 1970 & .036 & .044 & -.008 & .035 & .001 & 228.0 & .23 \\
\hline 1971 & .076 & .038 & .038 & .048 & .028 & 246.1 & .23 \\
\hline 1972 & .057 & .025 & .032 & .038 & .019 & 260.5 & .22 \\
\hline 1973 & -.003 & -.027 & .023 & -.011 & .007 & 259.6 & .20 \\
\hline 1974 & .039 & .060 & -.021 & .081 & -.042 & 269.9 & .19 \\
\hline 1975 & .255 & .217 & .038 & .224 & .032 & 348.4 & .21 \\
\hline 1976 & .159 & .141 & .018 & .154 & .006 & 408.5 & .23 \\
\hline
\end{tabular}

SourCES.-From 1916 to 1938, Board of Governors of the Federal Reserve System 1943, pp. 509-12 and issues of the Federal Reserve Bulletin (for holdings by the Federal Reserve). From 1939 to 1976, U.S. Council of Economic Advisers 1970, p. 255, 1976, p. 253, 1977, pp. 274-75; Treasury Bulletin (June 1977), p. 68; Board of Governors of the Federal Reserve System 1976, pp. 868, 869, 882. $B /(\bar{Y} \cdot P)$ is the ratio of $B$ to the nominal value of trend GNP. See table 3 for the definitions of $\bar{Y}$ and $P$.

NOTE. $-D B_{t} \equiv \log \left(B_{t}\right)-\log \left(B_{t-1}\right), \hat{D A}$ in col. 2 is the estimated value from the 1922-76 equation with the $R(1-\theta)$ coefficient constrained to equal one; in col. 4 it is the estumated value from the 1948-76 equation with the $\pi$-coefficient constrained to equal one. $D B R \equiv D B-D B, B$ is the end-of-year value in billions of dollars of privately held interest-bearing public debt at nominal par value. The gross debt includes fully guaranteed securities issued by the Federal Home Mortgage Corporation, Home Owners Loan Corporation, Reconstruction Finance Corporation, Commodity Credit Corporation, U.S. Housing Authority, and Federal Housing Administration. The amounts of these issues are significant from 1934-44. Non-interest-bearing debt has been excluded. The figures are net of holdings by the Federal Reserve and government agencies and trust funds.

behavior is a recent phenomenon. In particular, the estimated coefficient of the temporary income variable over the 1922-40 sample is $-1.97, \mathrm{SE}=0.39$. Although the pre-Depression years, 1922-29, are a part of this sample, it is clear from the separate coefficient estimate and standard error for this period, $-1.18, \mathrm{SE}=1.27$, that only a moderate amount of information on this coefficient is provided by the addition of these data. A meaningful test for a shift in countercyclical debt response beginning with the New Deal would have to bring in earlier evidence from the Gold Standard period..$^{24}$ I plan to carry out this extension at a later time.

The estimated constant term for the 1922-76 sample (with the coefficient of the $R[1-\theta]$ variable restricted to unity) is $0.012, \mathrm{SE}=$ .005 . (Since the dummy variable applies to the 1922-40 period, the

${ }^{24}$ One suggested explanation for the "excessive" countercyclical debt response is that it reflects the cross-sectional graduation of income tax rates, which might affect the time-series relation of taxes to income if there were substantial adjustment costs for changing tax laws over the business cycle. Under this interpretation, the countercyclical response would be weaker during the pre-World War I, non-income tax period. 
constant for these years would be $0.012-0.059=-0.047$.) Theoretically, with the value of $R(1-\theta)$ rather than $\pi$ held fixed, the constant should correspond to the difference between $\rho$, the growth rate of real GNP, and the anticipated after-tax real rate of return. Since the average growth rate of real GNP from 1922 to 1976 was 0.032 per year, the constant corresponds to an anticipated after-tax real rate of return for the post-1941 period of 0.020 per year. ${ }^{25}$

\section{The Level of Debt}

The theory predicts that the level of debt or the debt-income ratio would be irrelevant for current debt issue. I have tested this proposition by adding the variable, $B_{t-1} /\left(P_{t-1} \bar{Y}_{t-1}\right)$, to the estimating equation. The estimated coefficient of this variable differs insignificantly from zero in all cases-for example, over the $1922-76$ period with the coefficient of the $R(1-\theta)$ variable restricted to unity, the estimated coefficient is $-0.012, \mathrm{SE}=0.018$. This result supports the surprising proposition of the theory that the debt-income ratio does not have a "target" value but rather moves "randomly" in accordance with the realizations for the federal expenditure and income shocks.

\section{Level of Federal Spending}

The theory stresses the role of temporary government expenditure, as opposed to the level of spending (see, however, $n .17$ above). If the variable, $P_{t} \bar{G}_{t} / \bar{B}_{t}$, is added to the debt equation, its estimated coefficient differs insignificantly from zero in all cases. For example, over the 1922-76 sample with the coefficient of the $R(1-\theta)$ variable again restricted to one, the estimated coefficient is $0.022, \mathrm{SE}=0.017$.

\section{Change in Interest Rate}

An increase in interest rates should reduce the growth rate of public debt when measured at par values (see above). For the case where the $R(1-\theta)$ coefficient is constrained to one and for the 1922-76 sample, the estimated coefficient of the variable, $R G_{t}-R G_{t-1}$, is $-0.7, \mathrm{SE}=$ 1.3. A failure to isolate a significant effect of this variable may stem from improper measurement, since $R G_{t-1}$ should be replaced by an

\footnotetext{
${ }^{25}$ However, over the 1948-76 period with the $\pi$ variable held fixed, the estimated constant is $0.015, \mathrm{SE}=0.007$, which is well below the growth rate of real GNP. A possible interpretation is that the anticipated real rate of return for the post-1941 period is actually close to zero, and that the constant is below the growth rate because of the expectation that government spending will rise faster than income over time (see above).
} 
appropriately weighted average of past coupon rates. Therefore, the effect of this variable may be worth further examination.

\section{The Experience of Debt Issue from 1917 to 1976}

Table 3 contains values for the actual growth rate of nominal public debt, $D B$, since 1917. Estimated values and residuals from the 1922-76 equation (with the coefficient of the $R[1-\theta]$ variable set to one and with the estimates extrapolated to 1917-21) and from the 1948-76 equation with the coefficient of the $\pi$-variable set to one are also indicated. Values of the independent variables used in the estimating equations are shown in table 1.

The extrapolation of the 1922-76 equation captures well the extraordinarily high growth rates of public debt (starting from a low base of less than $\$ 1$ billion of debt in 1916) during World War I, 1917-18. The equation substantially overestimates the growth rate of debt from 1919 to 1921 . I suspect that this underestimation arises because a strong anticipated deflation after the war is not captured by the interest-rate variable. However, this conjecture cannot be tested without a direct measure of anticipated inflation.

The 1922-29 period exhibits negative values of $D B$, which are consistent with the negative values of $G-G$ during this period and with the absence of any important economic contraction from 1923 to 1929. The strongly positive growth rates of debt from 1931 to 1940 reflect, first, the countercyclical response to the depression (with a peak effect from 1932 to 1934) and, second, the impact of a sharp increase in federal spending, especially from 1934 to 1936 . The value of +0.08 for the $P(G-\bar{G}) / \bar{B}$ variable in 1934 , as contrasted with -0.08 for 1929 , implies, by itself, that the value of $\hat{D B}$ for 1934 exceeds that for 1929 by 0.26 per year. The even sharper rise in federal spending during World War II accounts for the vast increase in debt for 1941-45.

The first years of the post-World War II period, 1946-48, show negative growth rates of debt, which are associated with the sharp cutback in federal spending. This pattern is interrupted by the 1949 recession but is resumed in 1950 . The expansion of federal spending associated with the Korean War, especially in 1952-53, is reflected in higher growth rates of debt. The 1954 "recession" is offset by a substantial drop in the federal spending variable to produce a moderate growth rate of debt for that year. Throughout the period from 1955 to 1965 , the relatively slow growth in federal spending (relative to the average since 1860 of 5.6 percent per year) is a factor that lowers the growth of debt.

The boom in 1955 produces an estimated value $\widehat{D B}$ of -0.027 , 
although the actual value of zero is substantially higher. From 1956 to 1958 the values of $D B$ are below the estimated values-in particular, the expansion of debt during the 1958 contraction is less vigorous than would have been expected. This pattern of weaker than expected debt expansion applies also to the $1960-63$ period. This relationship is reversed for 1964-65-apparently reflecting the positive effect on debt issue of the celebrated 1964-65 tax cuts. However, the residual from the 1922-76 equation for 1964 is only 0.004 . The 1965 residual, 0.014, shows a more substantial effect. An expansionary factor for 1967-68 is the rise in federal spending associated with the Vietnam War. An interesting note about the 1968 observation is that it shows a positive residual, which confirms the general belief that the "tax surcharge" for that year was quantitatively trivial. However, a negative residual does appear for 1969.

During the 1970 s the federal spending variable is again a negative contributor to the growth of debt. However, the anticipated rate of inflation becomes a significant positive element during this period$\pi$ rises from 0.014 in 1964 to 0.030 in 1967 and from 0.029 in 1968 to 0.062 in 1972, remaining at about 6 percent per year through 1976; the interest-rate variable, $R(1-\theta)$, rises steadily from 0.040 in 1964 to 0.070 in 1970 , and then varies between 0.063 and 0.078 for the $1970-76$ period. For the early 1970s the expected inflation factor is substantially offset only by the strong boom in 1973, which produces a single year of negative growth in the nominal debt. The recession that begins in 1974 returns the growth rate of debt to the positive range.

The vast debt explosion for 1975-76 has been widely noted. It is therefore of interest that the present analysis seems to account for this behavior reasonably well-the $1922-76$ equation yields a value for $\hat{D B}$ of 0.22 , as compared with an actual value of 0.26 . For 1976 the $\hat{D B}$ value is 0.14 , as compared with an actual value of 0.16 . It is important to note that the federal spending variable is not an element in these high values of debt growth. The major contributor is the strong recession (output 8 percent below trend in 1975), which produces a value of the pertinent variable, $\log (Y / \bar{Y}) \cdot P \bar{G} / \bar{B}$, for 1975 that is the highest magnitude, 0.095, of the entire 1922-76 sample! The effect of a given proportionate shortfall of income (in this case by 8 percent) on debt issue depends multiplicatively on the normal level of federal spending, because the product of $\log (Y / \bar{Y})$ and $\bar{G}$ indicates (if $G=\bar{G}$ ) the amount by which real taxes would be reduced if the tax-income ratio were to be kept constant. Because the value of $\bar{G}$ is much higher in 1975 than during the depth of the Great Depression in 1933 (where $\log [Y / \bar{Y}]=-0.40$ ), the smaller percentage output shortfall in 1975 is converted into a larger overall effect on debt issue. According to the 1922-76 equation, the temporary income variable for 1975 
raises $\widehat{D B}$ by 0.16 per year (relative to a situation in which $\log [Y / \bar{Y}]=$ 0 ) - that is, it accounts for $\$ 47$ billion out of the total debt increment during 1975 of $\$ 78$ billion. The second positive element for 1975 is the high anticipated rate of inflation $(\pi=0.060)$, which affects the value of $\widehat{D B}$ on a one-to-one basis and thereby accounts for $\$ 17$ billion of debt issue (relative to a situation where $\pi=0$ ).

For 1976 the reduced value of $\hat{D B}$ reflects principally the smaller magnitude of the temporary-income variable. The value of $\pi(0.062)$ remains high for this year.

It may be of interest to carry out a formal test of the hypothesis that the apparent debt explosion for 1975-76 is consistent with earlier experience. ${ }^{26} \mathrm{~A}$ test that the $1975-76$ observations conform with those from 1922 to 1974 yields the statistic, $F_{49}^{2}=1.9,5$ percent critical value $=3.2$. Therefore, the hypothesis of an unchanged structure for $1975-76$ is accepted by this test. An extrapolation of an equation that is estimated over the 1922-74 period yields values for 1975 of $\hat{D B}=$ 0.196 , residual $=0.059$; and for 1976 of $D B=0.127$, residual $=$ 0.032 . Hence, the observed values of $\hat{D B}$ for $1975-76$ are above the extrapolated estimates from the 1922-74 experience, but not significantly so.

\section{Concluding Remarks}

Natural extensions to the present analysis of public debt behavior have been noted in parts of the discussion above. Theoretical possibilities include the incorporation of currency issue, a rigorous application of optimal taxation theory to public debt determination (n. 7 above), and an explicit treatment of uncertainty about future government spending, national income, and so on. On an empirical level it would be useful to improve the measure of anticipated inflation to include a proper treatment of change-in-interest-rate effects, to test directly propositions concerning the unpredictability of federal tax rate changes, and to extend the analysis to earlier U.S. data. An investigation of the debt-creation process in the United Kingdom, which is currently being carried out by Benjamin and Kochin (1978), should provide interesting comparative evidence.

I have also begun a study that utilizes the present analysis to examine the effects of shifts between public debt and taxes on economic activity. This analysis stresses the distinction between customary debt movements - which may be measurable as the estimated value from a public debt equation-and the surprise part of these shifts. Theoreti-

\footnotetext{
${ }^{26} \mathrm{~A}$ difficulty with this test is that it is motivated entirely by the observation of a "high" realized value of $D B$. The statistical properties of the usual tests would therefore not hold.
} 
cally, the latter parts would have a stronger impact on output-in fact, the former parts would be neutral in some models. However, my preliminary results have not isolated important output effects of either component of public debt movements. The public debt theory developed in the present paper suggests a possible difficulty in isolating the business-cycle effects of the temporary tax changes that are associated with the usual view of fiscal policy. If the theory has some empirical validity, so that the principal movements in federal tax rates have, in fact, represented permanent changes-in the sense that future changes in rates were unpredictable-then the historical data would not provide much evidence about the impact of temporary changes in federal taxes.

\section{References}

$\rightarrow$ Barro, Robert J. "Are Government Bonds Net Wealth?" J.P.E. 82, no. 6 (November/December 1974): 1095-1117.

- "Optimal Revenue Collection and the Money Growth Rate." Unpublished paper, Univ. Rochester, 1976. (a)

$\rightarrow-$. "Reply to Feldstein and Buchanan." J.P.E. 84, no. 2 (April 1976): 343-49. (b)

- "Unanticipated Money Growth and Unemployment in the United States." A.E.R. 67 (March 1977): 101-15.

$\longrightarrow$ "Unanticipated Money, Output, and the Price Level in the United States."J.P.E. 86, no. 4 (August 1978): 549-80.

Barro, Robert J., and Fischer, Stanley. "Recent Developments in Monetary Theory." J. Monetary Econ. 2 (April 1976): 133-67.

Benjamin, Daniel K., and Kochin, Levis A. "The British National Debt." Unpublished paper, Univ. Washington, 1978.

Board of Governors of the Federal Reserve System. Banking and Monetary Statistics. Washington: Federal Reserve, 1943.

- Banking and Monetary Statistics, 1941-70. Washington: Federal Reserve, 1976.

Buchanan, James M. Public Principles of Public Debt. Homewood, Ill.: Irwin, 1958.

$\rightarrow \rightarrow$ "Barro on the Ricardian Equivalence Theorem." J.P.E. 84, no. 2 (April 1976): 337-42.

Dewey, D. R. Financial History of the United States. 11 th ed. London: Longmans Green, 1931.

Federal Reserve Bulletin, various issues.

Firestone, John M. Federal Receipts and Expenditures during Business Cycles. Princeton, N.J.: Princeton Univ. Press, 1960.

$\rightarrow$ Hall, Robert E. "Stochastic Implications of the Life Cycle-Permanent Income Hypothesis: Theory and Evidence." J.P.E. 86, no. 6 (December 1978): $971-87$.

Kydland, Finn, and Prescott, Edward C. "On the Possibility and Desirability of Stabilization Policy." Paper presented at the N.B.E.R. Conference on Rational Expectations and Economic Policy, Bald Peak, N.H., October 1978. 
McCallum, Bennett T., and Whitaker, J. K. "The Effectiveness of Fiscal Feedback Rules and Automatic Stabilizers under Rational Expectations." J. Monetary Econ., in press.

$\rightarrow$ O'Driscoll, Gerald P., Jr. "The Ricardian Nonequivalence Theorem." J.P.E. 85, no. 2 (February 1977): 207-10.

Prescott, Edward C. "Should Control Theory Be Used for Economic Stabilization?" In Optimal Policies, Control Theory and Technology Exports. Supplement to the J. Monetary Econ., 1977.

Ricardo, David. "On the Principles of Political Economy and Taxation." In The Works and Correspondence of David Ricardo, edited by P. Sraffa. Vol. 1. Cambridge: Cambridge Univ. Press, 1951. (a)

"Funding System." In The Works and Correspondence of David Ricardo, edited by P. Sraffa. Vol. 4. Cambridge: Cambridge Univ. Press, 1951. (b)

Sadka, Efraim. "A Theorem on Uniform Taxation." J. Public Econ. 7 (June 1977): 387-91.

$\rightarrow$ Sandmo, Agnar. "A Note on the Structure of Optimal Taxation." A.E.R. 64 (September 1974): 701-6.

Treasury Bulletin (June 1977).

U.S. Bureau of the Census. Historical Statistics of the United States, Colonial Times to 1970. Washington: Government Printing Office, 1975.

U.S. Council of Economic Advisers. Economic Report of the President. Washington: Government Printing Office, 1962, 1970, 1976, 1977.

U.S. Department of Commerce. Long Term Economic Growth, 1860-1970. Washington: Government Printing Office, 1973. The National Income and Product Accounts of the United States, 1929-74. Washington: Government Printing Office, 1976.

Survey of Current Business. Washington: Government Printing Office, July 1977. 